\title{
Human mesangial cells resist glycoxidative stress through an antioxidant response
}

\author{
MARIAPAOLA NITTI*, ANNA LISA FURFARO*, STEFANIA PATRIARCA, EMANUELA BALBIS, \\ CINZIA DOMENICOTTI, DAMIANO COTTALASSO, MARIA ADELAIDE PRONZATO, \\ UMBERTO MARIA MARINARI and NICOLA TRAVERSO
}

\author{
Department of Experimental Medicine, Section of General Pathology, \\ University of Genoa, 16132 Genoa, Italy
}

Received August 3, 2010; Accepted September 21, 2010

\section{DOI: 10.3892/ijmm.2010.576}

\begin{abstract}
The generation of advanced glycation end-products (AGE), the interaction with their receptors, the generation of reactive oxygen species, and the modulation of intracellular redox equilibrium are believed to be the main factors causing alterations of mesangial cell physiology leading to diabetic nephropathy. Normal human primary mesangial cells were exposed to glycoxidative stress by culture in high glucose (HG) or treatment with AGE for up to 6 days. In both cases only a moderate generation of reactive oxygen species and production of HNE-protein adducts were induced while protein nitrotyrosination was not affected. Moreover, HG and AGE caused a significant antioxidant response, confirmed by the induction of heme oxygenase 1 and the consumption of vitamin E. Glutathione was decreased only by HG. Mesangial cell proliferation and viability were slightly affected by HG and AGE. Furthermore, both treatments failed to influence TGF- $\$ 1$ and MCP-1 secretion and to modulate RAGE and collagen IV expression. We believe that normal human mesangial cells can resist glycoxidative stress by the observed antioxidant response. These results support the concept that mesangial cells are only partly responsible for the onset and progression of diabetic nephropathy and that the role of other cell types, such as podocytes and endothelial cells, should be taken into consideration.
\end{abstract}

\section{Introduction}

Glycoxidation, a process involving both glycative and oxidative mechanisms (1), is widely believed to play a major role in the pathogenesis of several long-term diabetic complications, particularly nephropathy (2). Glycoxidation causes the generation of a wide range of molecular structures,

Correspondence to: Dr Nicola Traverso, DIMES, Section of General Pathology, Via LB Alberti 2, 16132 Genoa, Italy

E-mail: nicola.traverso@unige.it; nictraverso@yahoo.it

*Contributed equally

Key words: diabetes, mesangium, glycoxidation, heme oxygenase mainly on proteins, that are able to exert several detrimental effects. These molecular structures are called advanced glycoxidation end-products (AGE). The simple presence of AGE in proteins, not only in long-lived proteins such as crystallins or collagens but also in intracellular proteins (3), can induce structural and functional alterations, leading to increased rigidity, decreased elasticity, reduced turn-over and enzymatic dysfunction. Moreover, the recognition of several cell surface receptors for AGE (4) has aroused increasing interest in investigating the consequences of AGE interaction with their cellular receptors. In particular, the binding of AGE with RAGE has been shown to be connected to signal transduction pathways, leading to increased oxidative stress and various cell responses, which may be involved in the pathogenesis of diabetic complications (5).

Since diabetic nephropathy is characterized by increased deposition of mesangial matrix in the glomerulus, mesangial cells have been attributed a central role in the pathogenesis of this glomerular alteration (6). Exposure of mesangial cells in vitro to a high glucose concentration or to glycated proteins has been reported to result in increased production of matrix proteins and decreased production of matrix metalloproteases, indicating that mesangial cells can react to diabetes-like conditions by assuming a profibrogenic attitude $(7,8)$. The mechanisms underlying mesangial cell response probably depend on the increased levels of oxidative stress (9).

We previously demonstrated that certain antioxidants are able to protect streptozotocin-induced diabetic rats from several morphological and molecular aspects of diabetic nephropathy $(10,11)$. Therefore, we decided to investigate the possible protective role of these antioxidants on mesangial cells in vitro, when stressed with diabetes-like conditions, such as exposure to a high glucose (HG) culture or to AGE proteins.

However, in the present study, we found that both HG and AGE barely affected cell proliferation and viability and failed to induce a profibrogenic attitude in normal human mesangial cells, which were able to maintain a mild level of oxidative stress, while consuming vitamin $\mathrm{E}$ and up-regulating heme oxygenase-1 (HO-1) expression.

\section{Materials and methods}

Cell culture and treatments. Normal human mesangial cells (NHMCs) were purchased (2 different batches) from Cambrex 
Bio Science and maintained according to the company's instructions in the Mesangial Cell Growth Medium Bullet kit $\left(\mathrm{MsGM}^{\mathrm{TM}}\right)$, containing $5 \mathrm{mM}$ glucose, supplemented with 5\% FBS and MsGM SingleQuots supplied by the same company. Cells were subcultured every 5 days at $1: 4$, and the experiments were carried out within the 10th doubling of the cells.

Cells were exposed to the normal growth medium (CTR, control) or to the same medium supplemented with $25 \mathrm{mM}$ glucose (HG, high glucose), $200 \mu \mathrm{g} / \mathrm{ml}$ bovine serum albumin (BSA) or AGE-modified BSA (AGE-BSA), or $100 \mu \mathrm{m} \mathrm{H}_{2} \mathrm{O}_{2}$. Exposures were extended for up to 6 days. Every two days, the media were removed, collected and substituted with fresh media with the same characteristics. Some samples were exposed to $0.5-1.0 \mathrm{mM} \mathrm{H}_{2} \mathrm{O}_{2}$ for 1-3 h.

AGE-BSA was obtained by incubating BSA $(10 \mathrm{mg} / \mathrm{ml}$ in PBS, $10 \mathrm{mM}$, pH 7.4) with $50 \mathrm{mM}$ ribose for 6 days. AGEmodification was assessed by fluorescence detection $(370 \mathrm{~nm}$ ex/440 nm em) and evaluation of carboxymethyl-lysine by Western blot analysis (12).

Cell proliferation and viability. Cell proliferation was evaluated by cell count using trypan blue dye, and cell viability was assessed using the LDH release test (Cytotox 96, non-radioactive cytotoxicity assay; Promega, Madison, WI, USA).

Evaluation of peroxides and superoxide anion generation. Evaluation of peroxides (13) was performed using the dichloro-fluorescein (DCF) test. Briefly, after treatments, cells were washed with PBS and exposed to $5 \mu \mathrm{M}$ dichlorodihydro-fluorescein diacetate (DCF-DA) for $30 \mathrm{~min}$ at $37^{\circ} \mathrm{C}$. Cells were then washed twice and scraped off in $1 \mathrm{ml}$ of PBS; cells were subsequently sonicated. Fluorescence of cell lysates was analyzed using the Perkin-Elmer LS-5 Luminescence spectrometer (498 nm ex/525 nm em). Results are expressed as arbitrary units of fluorescence (AUF)/mg protein.

Superoxide anion production was evaluated using the dihydroethidium test. At the end of the treatments, cells were washed and exposed to $10 \mu \mathrm{M}$ dihydroethidium for $30 \mathrm{~min}$ at $37^{\circ} \mathrm{C}$. Cells were then washed and observed by fluorescence microscopy (14).

Analysis of RAGE and HO-1 expression and carboxymethyllysine (CML)-, nitro- and HNE-protein adducts. Protein expression levels were evaluated by a Western blot analysis standard technique on Hybond-P PVDF membranes using the following primary antibodies: 1:20000 mouse anti-CML clone no. NF-1G (Wako Chemicals GmbH, Neuss, Germany); 1:1000 mouse anti-nitrotyrosine (Abcam, Cambridge, UK); 1:80000 rabbit anti-HNE (Alpha Diagnostic International, San Antonio, TX, USA); 1:4000 mouse anti-RAGE (MilliporeChemicon International, Billerica, MA, USA); and 1:250 mouse anti-HO-1 (Abcam). In addition, anti-mouse or anti-rabbit horseradish peroxidase-conjugated antibodies and the ECL Plus detection system (GE Healthcare-Amersham, Milan, Italy) were used according to the manufacturer's instructions.

Analysis of transforming growth factor (TGF)- $\beta 1$ and monocyte chemoattractant protein (MCP)-1. Evaluation of
TGF- 11 and MCP-1 was performed using ELISA by means of the following kits: DuoSet Human TGF-ß1 (R\&D Systems, Minneapolis, MN, USA) which also detects latent TGF- $\beta 1$ and the (h)MCP-1 Biotrak ELISA system (GE HealthcareAmersham).

Immunocytochemistry for HNE-protein adducts. Immunocytochemistry (ICC) for HNE-protein adducts was performed on chamber slides by standard protocol. Briefly, at the end of the programmed exposure time, cells were fixed in buffered $4 \%$ paraformaldehyde and permeabilized with $0.1 \%$ Triton $\mathrm{X}-100$. Endogenous peroxidase activity was quenched by incubation with $1 \% \mathrm{H}_{2} \mathrm{O}_{2}$, and non-specific binding sites were blocked with $5 \%$ goat serum. After overnight incubation with 1:10,000 rabbit anti-HNE antiserum (Alpha Diagnostic International) and a 45-min incubation with 1:1000 anti-rabbit biotinylated antibody, cells were exposed to streptavidinbiotinylated horseradish peroxidase StreptABComplex/HPR (Dako, Glostrup, Denmark), and 3,3'-diaminobenzidine $/ \mathrm{H}_{2} \mathrm{O}_{2}$ (Dako) was applied until the reaction product was visualized (3 min).

Analysis of GSH and vitamin E level. Glutathione (GSH) was evaluated using high-performance liquid chromatography (HPLC) according to Fariss and Reed (15). Briefly, cells were harvested in PBS containing $10 \%$ perchloric acid and $1 \mathrm{mM}$ BPDS. After vortexing and precipitation of the proteins by centrifugation, thiol groups were blocked with iodoacetic acid (IAA) at an alkaline $\mathrm{pH}$, and analytes were then converted to 2,4-dinitrophenyl derivatives with $1 \%$ 1-fluoro2,4-dinitrobenzene (FDNB) at $4^{\circ} \mathrm{C}$ in the dark overnight. Quantitative determination of derivatized analytes was performed by HPLC; the HPLC system was equipped with an $\mathrm{NH}_{2}$ Spherisorb column and a UV detector set at $365 \mathrm{~nm}$; the flow rate was $1.5 \mathrm{ml} / \mathrm{min}$. The mobile phase was maintained at $80 \% \mathrm{~A}(80 \%$ methanol) and $20 \% \mathrm{~B}(0.5 \mathrm{M}$ sodium acetate in $64 \%$ methanol) for $5 \mathrm{~min}$, followed by a 10 -min linear gradient to $1 \% \mathrm{~A}$ and $99 \% \mathrm{~B}$; the mobile phase was maintained at $99 \%$ B until GSSG eluted. Total GSH content was evaluated in the chromatograms as GSH+2GSSG and expressed in GSH equivalents (16).

Determination of vitamin E was performed using HPLC according to the method of Lang et al (17). Briefly, cell cultures were harvested in $10 \mathrm{mM}$ PBS and mechanically disrupted; tocopherol acetate (as internal standard, final concentration $1.75 \mu \mathrm{M}$ ), BHT (final concentration $0.25 \mathrm{mg} / \mathrm{ml}$ ) and SDS (final concentration $10 \mathrm{mM}$ ) were added to the mixture. After adding an equal volume of ethanol, the mixture was extracted with heptane (volume/volume). The heptane layer was dried under nitrogen, and the residue was re-dissolved in methanol. An aliquot was analyzed by HPLC ( $\mu$ Bondapak C18 column; size, 3.9 x 300 mm; Waters, Milford, MA, USA; pure methanol as mobile phase; UV detection at $292 \mathrm{~nm}$ ). Quantitation was performed by means of reference chromatograms of a standard solution of vitamin $\mathrm{E}$.

Analysis of heme oxygenase-1 (HO-1) and collagen IV expression. HO-1 and collagen IV mRNA expression was evaluated in a reverse transcription-polymerase chain reaction (RT-PCR). Total RNA was extracted using Trizol 
reagent (Invitrogen, Milan, Italy) according to the manufacturer's instructions. RNA was reverse transcribed into cDNA by random hexamer priming and SuperScript ${ }^{\mathrm{TM}}$ II reverse transcriptase (Invitrogen). Amplification of cDNA by PCR was performed by using 2X PCR Master Mix (Fermentas, Milan, Italy) and specific primers for human HO-1 and collagen IV, synthesized by TIB MolBiol (Genoa, Italy); control reactions were performed with primers specific for human GAPDH. The sequences of the primers were as follows: HO-1 Fw, 5'gct caa cat cca gct ctt tga gg 3'; HO-1 $\mathrm{Rv}, 5^{\prime}$ gac aaa gtt cat ggc cct ggg a 3' (284 bp) (30 cycles: $95^{\circ} \mathrm{C}$ for $1 \mathrm{~min}, 62^{\circ} \mathrm{C}$ for $1 \mathrm{~min}, 72^{\circ} \mathrm{C}$ for $\left.2 \mathrm{~min}\right)(18)$; collagen IV Fw, $5^{\prime}$ cgg ggt tac aag gtg tca ttg g $3^{\prime}$; collagen IV Rv, 5' gcc aag tat ctc acc tgg 3' (332 bp) (designed on the sequence GenBank NM_001854; 30 cycles: $95^{\circ} \mathrm{C}$ for $45 \mathrm{sec}$, $55^{\circ} \mathrm{C}$ for $45 \mathrm{sec}, 72^{\circ} \mathrm{C}$ for $60 \mathrm{sec}$ ); GAPDH Fw, $5^{\prime}$ gtc ttc acc acc atg gag aa $3^{\prime}$; GAPDH Rv, $5^{\prime}$ atc cac agt ctt ctg ggt gg $3^{\prime}$ (266 bp) $\left(30\right.$ cycles: $95^{\circ} \mathrm{C}$ for $1 \mathrm{~min}, 59^{\circ} \mathrm{C}$ for $1 \mathrm{~min}, 72^{\circ} \mathrm{C}$ for $2 \mathrm{~min}$ ) (18). The amplification products were separated by electrophoresis on $1.5 \%$ agarose ethidium bromide gel and analyzed using the Gel Doc 2000 densitometer by means of 'Molecular Analyst' software (both from BioRad, Milan, Italy).

Statistical analyses. Results were expressed as mean \pm SD from at least three independent experiments. The statistical significance of parametric differences among sets of experimental data was evaluated by ANOVA and Newman Keuls post-test for multiple comparisons. When comparing two groups of data, the t-test was used.

\section{Results}

Intracellular oxidative stress. Evaluation of the intracellular oxidative state (Fig. 1) revealed a slight but significant sensitivity of NHMCs to AGE, $\mathrm{HG}$ or $\mathrm{H}_{2} \mathrm{O}_{2}$. Evaluation of peroxides using DCF-DA (Fig. 1a) showed significantly increased production after a 2-day exposure to AGE, $\mathrm{HG}$ or $100 \mu \mathrm{M} \mathrm{H}_{2} \mathrm{O}_{2}$; no significant changes in peroxide generation were observed at the other experimental times considered (up to 6 days). However, superoxide production, as assessed by the dihydroethidium test (Fig. 1b), was increased from $6 \mathrm{~h}$ up to 6 days of exposure to AGE, $\mathrm{HG}$ or $100 \mu \mathrm{M} \mathrm{H}_{2} \mathrm{O}_{2}$. Western blot analysis did not show any significant difference in the level of nitrotyrosine adducts after up to 6 days of AGE, HG or $100 \mu \mathrm{M} \mathrm{H}_{2} \mathrm{O}_{2}$ exposure (Fig. 1c).

Western blot analyses showed moderate increases in the immunoreactivity for HNE-adducts in all treatments from 2 days onwards, particularly for bands between 55 and $72 \mathrm{kDa}$; after 6 days of treatment with AGE, $\mathrm{HG}$ and $100 \mu \mathrm{M} \mathrm{H}_{2} \mathrm{O}_{2}$, the increments were $+25,+30$ and $+35 \%$, respectively, in comparison to the untreated cells (Fig. 1c). Moreover, when evaluated using ICC (Fig. 2), the mesangial cells showed a slight but appreciable increase in HNE-adducts after the same treatments. The accuracy of the ICC assay was confirmed by using mouse anti-actin antibody as positive staining and mouse anti-cytokeratin 18 antibody as negative staining.

Antioxidant defenses. Cell treatment with $\mathrm{HG}$ and $100 \mu \mathrm{M}$ $\mathrm{H}_{2} \mathrm{O}_{2}$ for 6 days induced a moderate decrease ( -15 and $-22 \%$, respectively) in GSH content in comparison to the untreated cells (Fig. 3a). It should be considered that, under the same culture conditions, fibroblasts contained much less GSH than the mesangial cells, and that the same $\mathrm{H}_{2} \mathrm{O}_{2}$ exposure induced a dramatic decrease in GSH ( $-90 \%$ vs. control) (data not shown).

Vitamin E was significantly reduced in mesangial cells after a 6-day exposure to AGE (-42\%), HG (-44\%) or $100 \mu \mathrm{M}$ $\mathrm{H}_{2} \mathrm{O}_{2}$ (-39\%) (Fig. 3b).

Regarding HO-1 mRNA expression, AGE, HG and $100 \mu \mathrm{M}$ $\mathrm{H}_{2} \mathrm{O}_{2}$ treatments were able to increase the expression of HO-1 in comparison to the control cells: AGE induced a strong and prolonged induction from 2 days onwards ( $\sim 5$-fold increase in comparison to CTR at the same time); HG caused a slower increase (maximum $\sim 3$-fold increase at day 4 in comparison to CTR at the same time), while $100 \mu \mathrm{M} \mathrm{H}_{2} \mathrm{O}_{2}$ was able to induce an 8-fold increase at $24 \mathrm{~h}$ (vs. CTR at $24 \mathrm{~h}$ ), followed by a decrease to lower levels of induction (Fig. 4). Western blot analysis of protein expression provided analogous results (data not shown).

Cell proliferation and viability. Proliferation of NHMCs was evaluated by cell count. Exposure to AGE or HG for 6 days revealed a slight reduction in cell proliferation $(-15 \%$ in comparison with control cells) while exposure to $100 \mu \mathrm{M}$ $\mathrm{H}_{2} \mathrm{O}_{2}$ induced a more pronounced decrease in cell proliferation ( $-40 \%$ vs. CTR).

Exposure of NHMCs to AGE, HG or $100 \mu \mathrm{M} \mathrm{H}_{2} \mathrm{O}_{2}$ for up to 6 days did not induce any significant alteration of cell viability, as measured by the LDH release test (data not shown).

Mesangial cells proved rather resistant even when exposed to higher $\mathrm{H}_{2} \mathrm{O}_{2}$ concentrations; $0.5 \mathrm{mM} \mathrm{H} \mathrm{H}_{2} \mathrm{O}_{2}$ did not affect cell viability even after $3 \mathrm{~h}$, and after $1 \mathrm{~h}$ of treatment with $1 \mathrm{mM} \mathrm{H}_{2} \mathrm{O}_{2}$, cell viability was still $50 \%$ in comparison to the control cells.

TGF- $\beta 1$ and MCP-1 production and collagen IV expression. TGF- $\beta 1$ production was evaluated both inside the cells and in the medium. NHMCs exposed to the various treatments did not show any variation in intracellular TGF- $\$ 1$ content at any time up to 6 days (data not shown). No secreted TGF-ß1 was detected before $24 \mathrm{~h}$ of exposure. Afterwards, the quantity of secreted TGF- $\$ 1$ increased progressively, but no significant differences were detected at any time among the various exposures (Fig. 5a). Similar results were obtained for MCP-1 secretion (data not shown). Moreover, neither AGE nor HG exposure had an effect on the expression of collagen IV, as revealed by RT-PCR analysis (Fig. 5b).

RAGE expression. No effects of AGE, $\mathrm{HG}$ or $100 \mu \mathrm{M} \mathrm{H}_{2} \mathrm{O}_{2}$ exposure on RAGE protein expression level at any experimental time during the 6 days of treatment were noted (Fig. 6).

\section{Discussion}

Many researchers have reported that in vitro exposure to HG or AGE brings about several pathologic effects on various cell types (e.g. tubular epithelium, vascular smooth muscle 
a)

Peroxides

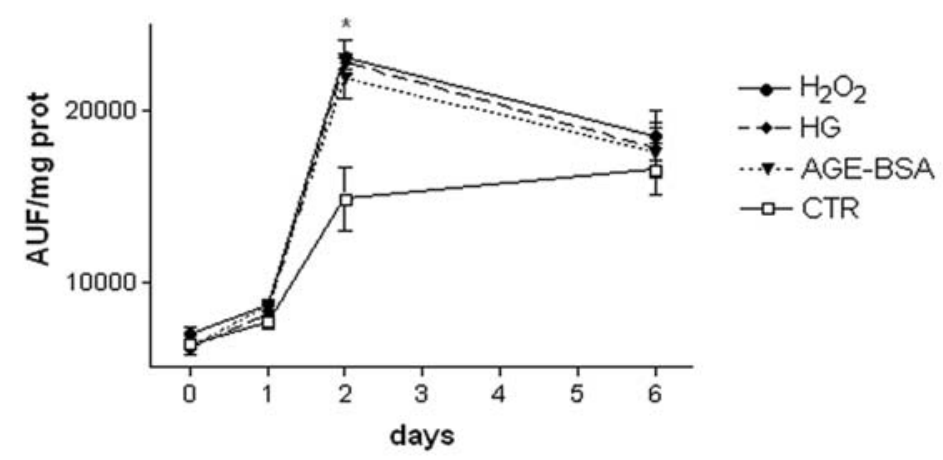

b)

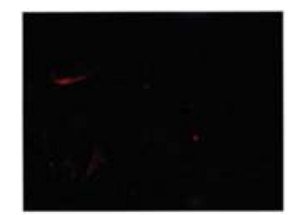

CTR

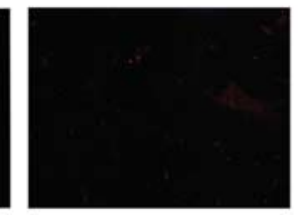

BSA

Superoxide anion

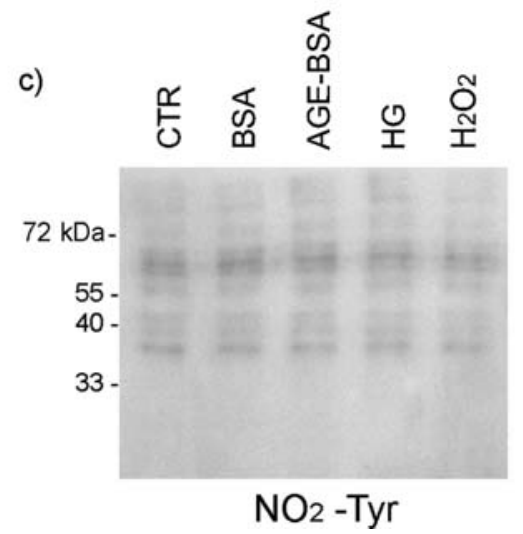

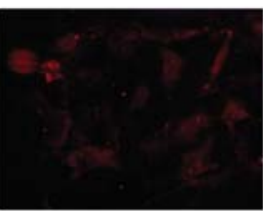

AGE-BSA

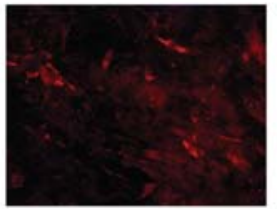

HG

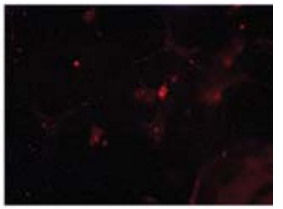

$\mathrm{H}_{2} \mathrm{O}_{2}$

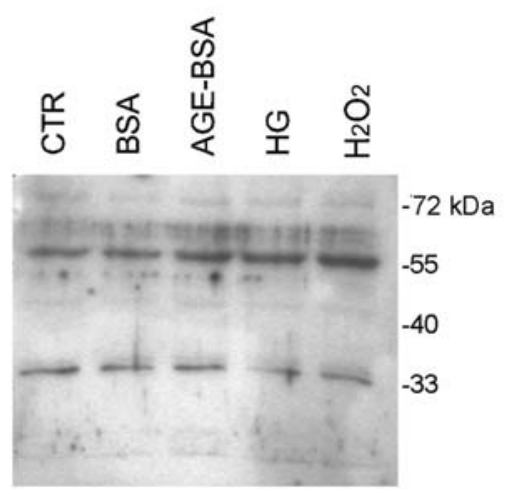

HNE-adducts

Figure 1. (a) Evaluation of peroxide production by the DCF-DA test during the 6 days of treatment. Statistics included ANOVA and Newman Keuls post-test; ${ }^{*} \mathrm{p}<0.05$ vs CTR at the same time. Results are expressed as the mean \pm SEM. (b) Evaluation of superoxide anion production by the dihydroethidium test. The panels are representative of three separate experiments at $48 \mathrm{~h}$ of treatment. Analogous results were obtained at each experimental time tested. (c) Evaluation of protein nitrotyrosination and HNE-adducts by Western blotting. The panels are representative of three separate experiments at 6 days of treatment.

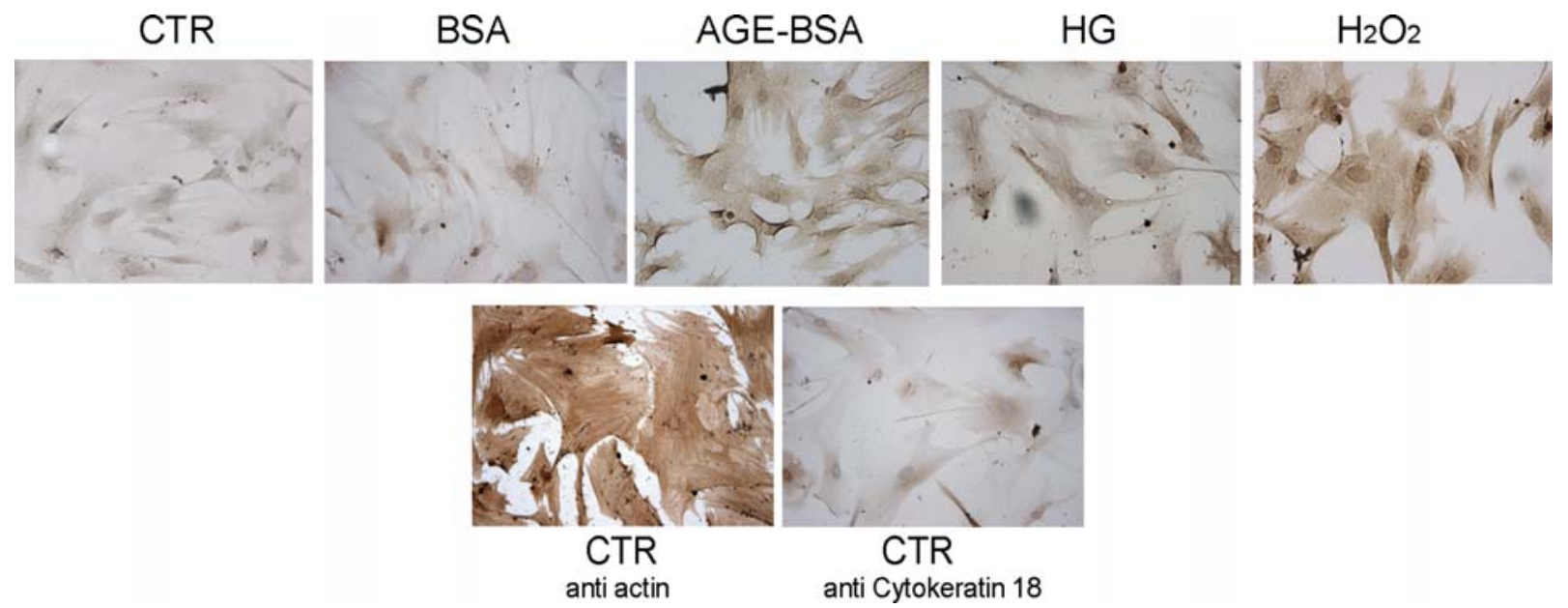

Figure 2. Evaluation of HNE-adducts by immunohistochemistry. The panels are representative of three separate experiments at 48 h of treatment. Analogous results were obtained at each experimental time tested. Anti-actin and anti-cytokeratin reactions are shown as positive and negative staining, respectively. 
a)

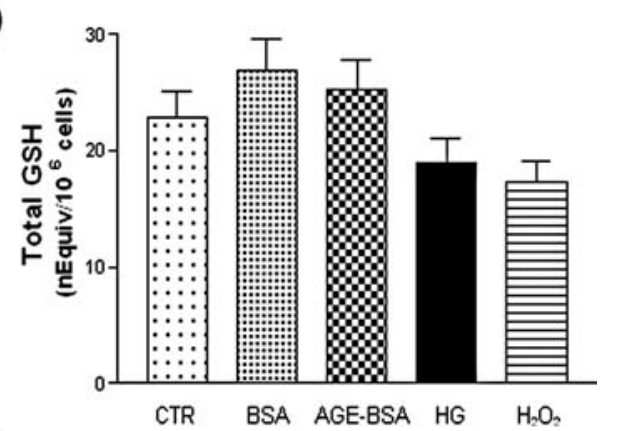

b)

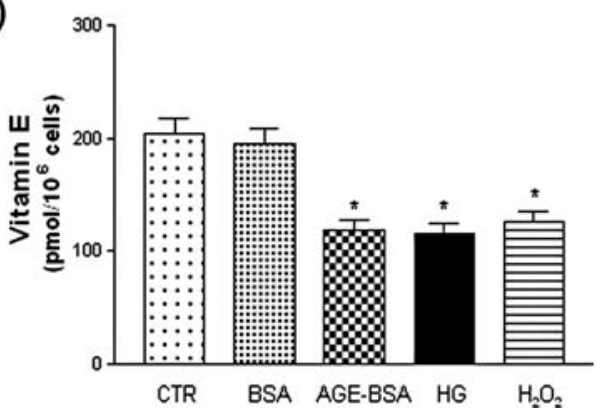

Figure 3. (a) Total glutathione (GSH) content evaluated by HPLC after derivatization with FDNB after 6 days of treatment. Results are expressed as the mean \pm SEM. (b) Vitamin E content evaluated by HPLC after 6 days of treatment. Statistics included ANOVA and Newman Keuls post-test; "p $<0.05$ vs CTR. Results are expressed as the mean \pm SEM.
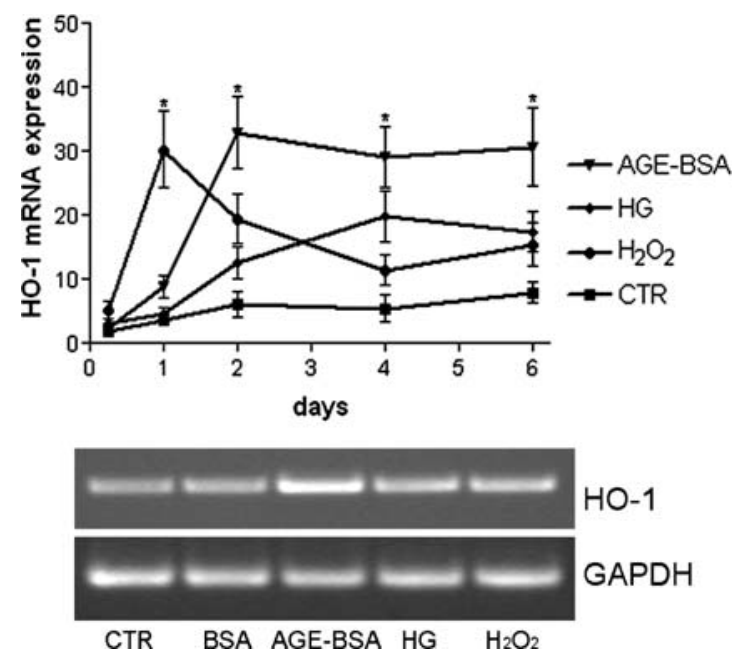

Figure 4. Upper panel: HO-1 mRNA expression evaluated by RT-PCR throughout the 6 days of treatment. Results for BSA were analogous to CTR (data not shown). Statistics included ANOVA and Newman Keuls post-test; " $p<0.05$ vs CTR at the same time. Results are expressed as the mean \pm SEM. Lower panel: representative gel of HO-1 expression after 6 days of treatments. GAPDH was used as the housekeeping gene.

cells, vascular and glomerular endothelium) $(9,19-23)$. The effects observed by these researchers included alterations in proliferation, viability, cell function and protein expression. Therefore, cell exposure to HG or AGE is believed to be involved in the pathogenesis of diabetic complications.

HG or AGE exposure has been observed to elicit pathologic responses in mesangial cells as well, such as peroxide a)

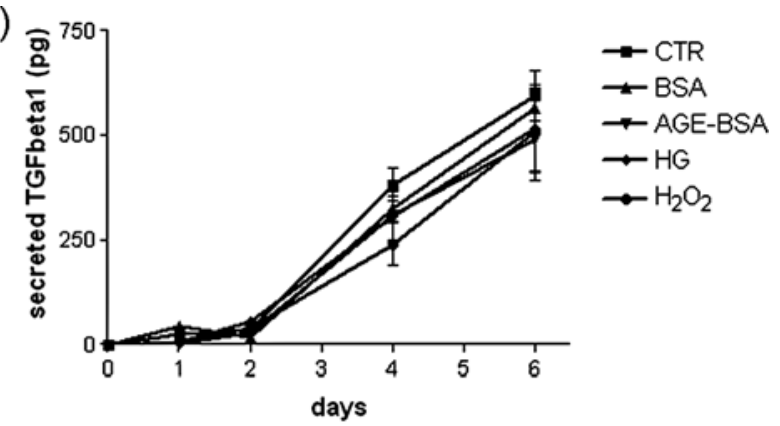

b)

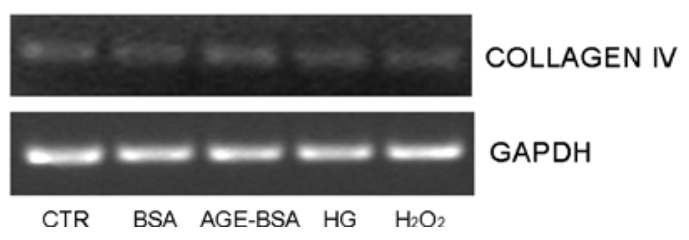

Figure 5. (a) Total TGF-ß1 secreted during the 6 days of treatment. No significant differences were noted at any time. Results are expressed as the mean \pm SEM. (b) Expression of collagen IV , as evaluated by RT-PCR. GAPDH was used as the housekeeping gene. The panels are representative of three separate experiments at 6 days of treatment.

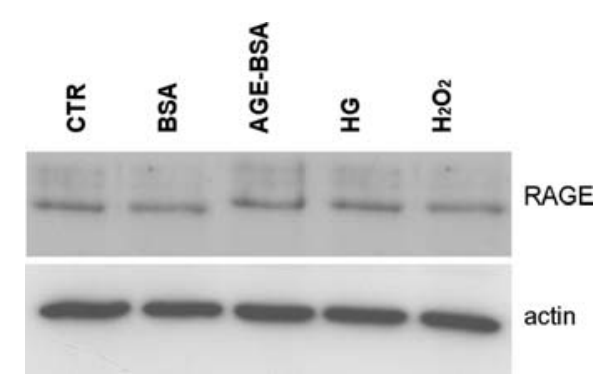

Figure 6. Evaluation of RAGE by Western blotting. B-actin was evaluated as the reference protein. The panel is representative of three separate experiments at day 6 of treatment.

production, activation of transcription factors, modulation of gene expression, matrix deposition and the inhibition of matrix remodeling $(6,8,24-28)$. Since matrix accumulation is a central mechanism of diabetic glomerulopathy, and since glomerular matrix is secreted by mesangial cells, it is widely believed that mesangial cells play a major role in the development of diabetic glomerulopathy $(6,9)$. The reaction of mesangial cells to $\mathrm{HG}$ or AGE has, therefore, been regarded as one of the main pathways leading to diabetic glomerulopathy.

In a previous study (10), we observed that some specific antioxidants conferred dramatic protection against morphological and molecular aspects of glomerulopathy in streptozotocin-induced diabetic rats. Therefore, we decided to investigate the effects of the same antioxidants on mesangial cells exposed in vitro to diabetes-like conditions ( $\mathrm{HG}$ or AGE), and we used a commercially available primary cell culture of normal human mesangial cells (NHMCs). Yet, when we tested the effects of $\mathrm{HG}$ and AGE exposure on 
NHMCs, surprisingly we found that the NHMCs were rather resistant to such treatments.

After AGE, $\mathrm{HG}$ or $\mathrm{H}_{2} \mathrm{O}_{2}$ treatments, peroxide overproduction was moderate, with no changes in the level of protein nitrotyrosination and a mild increase in the generation of HNE-protein adducts. This was accompanied by a mild consumption of GSH, a noticeable decrease in vitamin $\mathrm{E}$ and a considerable induction of HO-1. Proliferation and viability were virtually unaffected.

Furthermore, $\mathrm{HG}, \mathrm{AGE}$ and $\mathrm{H}_{2} \mathrm{O}_{2}$ exposure did not affect the secretion of chemical mediators involved in inflammation and matrix deposition, such as TGF- 31 and MCP-1; the same treatments were also unable to induce the expression of collagen IV. These results indicated that the NHMCs did not exhibit pro-fibrogenic behavior despite exposure to $\mathrm{HG}$ or AGE.

Finally, $\mathrm{HG}, \mathrm{AGE}$ and $\mathrm{H}_{2} \mathrm{O}_{2}$ exposure failed to affect the expression of RAGE, which could sensitize the cells to glycoxidative damage. An increase in RAGE expression is generally linked to an intracellular redox imbalance, which acts on the RAGE gene induction through NF- $\mathrm{B}$ activation (29). Therefore, this result underlines once again the basic resistance of NHMCs to pro-oxidant treatments.

We believe that the resistance of NHMCs to glycoxidative stress is, in all probability, due to an efficacious protective response, shown by the consumption of antioxidants and the induction of HO-1. In this context, it should also be noted that NHMCs demonstrated GSH levels considerably higher than fibroblasts.

We are aware of the amount of scientific data indicating that mesangial cells are susceptible to glycoxidative stress and respond by assuming a fibrogenic attitude (30-33); however, while those data were mainly obtained with 'homemade' primary cultures, foetal, non-human, or virus-modified mesangial cells $(8,25,34,35)$, commercially available normal human mesangial cells were used in the present study, which should be considered to be more reliable.

In conclusion, we are not casting doubts on the role of glycoxidative stress in the pathogenesis of diabetic nephropathy, also confirmed by our previous data obtained in vivo (10). Nevertheless, caution should be exercised in attributing an absolutely central role to mesangial cells in the pathogenesis of human diabetic glomerulopathy; mesangial cells may be less sensitive to the diabetes-induced alterations of the microenvironment than is generally believed. Moreover, many important observations on the role of podocytes (36-43) and glomerular endothelial cells $(41,44-48)$ in the pathogenesis of diabetic glomerulopathy have been reported in the literature. Therefore, the role of these other cells should be considered, together with the role of mesangial cells, to fully understand and verify the involvement of glycoxidative stress in the onset and progression of diabetic nephropathy.

\section{Acknowledgements}

We thank Mr. Giuseppe Catalano (DIMES, University of Genoa, Italy) for his technical assistance. Grants were provided by MIUR 20077S9A32_002, MIUR 2008N9N9KL_002 and the University of Genoa.

\section{References}

1. Fu MX, Wells-Knecht KJ, Blackledge JA, Lyons TJ, Thorpe SR and Baynes JW: Glycation, glycoxidation, and cross-linking of collagen by glucose. Kinetics, mechanisms, and inhibition of late stages of the Maillard reaction. Diabetes 43: 676-683, 1994.

2. Vlassara H and Palace MR: Glycoxidation: the menace of diabetes and aging. Mt Sinai J Med 70: 232-241, 2003.

3. Degenhardt TP, Thorpe SR and Baynes JW: Chemical modification of proteins by methylglyoxal. Cell Mol Biol 44: 1139-1145, 1998

4. Vlassara H, Li YM, Imani F, et al: Identification of galectin-3 as a high-affinity binding protein for advanced glycation end products (AGE): a new member of the AGE-receptor complex. Mol Med 1: 634-646, 1995.

5. Hori O, Yan SD, Ogawa S, et al: The receptor for advanced glycation end-products has a central role in mediating the effects of advanced glycation end-products on the development of vascular disease in diabetes mellitus. Nephrol Dial Transplant 11 (Suppl 5): 13-16, 1996.

6. Mason RM and Wahab NA: Extracellular matrix metabolism in diabetic nephropathy. J Am Soc Nephrol 14: 1358-1373, 2003.

7. Wahab NA, Harper K and Mason RM: Expression of extracellular matrix molecules in human mesangial cells in response to prolonged hyperglycaemia. Biochem J 316: 985-992, 1996.

8. McLennan SV, Martell SY and Yue DK: High glucose concentration inhibits the expression of membrane type metalloproteinase by mesangial cells: possible role in mesangium accumulation. Diabetologia 43: 642-648, 2000.

9. Lee HB, Yu MR, Yang Y, Jiang Z and Ha H: Reactive oxygen species-regulated signaling pathways in diabetic nephropathy. J Am Soc Nephrol 14: S241-S245, 2003.

10. Odetti P, Pesce C, Traverso N, et al: Comparative trial of Nacetyl-cysteine, taurine, and oxerutin on skin and kidney damage in long-term experimental diabetes. Diabetes 52: 499-505, 2003.

11. Furfaro AL, Menini S, Patriarca S, et al: HNE-dependent molecular damage in diabetic nephropathy and its possible prevention by $\mathrm{N}$-acetyl-cysteine and oxerutin. Biofactors 24 : 291-298, 2005.

12. Nitti M, Furfaro AL, Traverso N, et al: PKC delta and NADPH oxidase in AGE-induced neuronal death. Neurosci Lett 416: 261-265, 2007.

13. Zhang C, Gong Y, Ma H, An C, Chen D and Chen ZL: Reactive oxygen species involved in trichosanthin-induced apoptosis of human choriocarcinoma cells. Biochem J 355: 653-661, 2001.

14. Dong F, Zhang $\mathrm{X}$ and Ren J: Leptin regulates cardiomyocyte contractile function through endothelin-1 receptor-NADPH oxidase pathway. Hypertension 47: 222-229, 2006.

15. Fariss MW and Reed DJ: High-performance liquid chromatography of thiols and disulfides: dinitrophenol derivatives. Methods Enzymol 143: 101-109, 1987.

16. Sies H: Glutathione and its role in cellular functions. Free Radic Biol Med 27: 916-921, 1999.

17. Lang JK, Gohil K and Packer L: Simultaneous determination of tocopherols, ubiquinols, and ubiquinones in blood, plasma, tissue homogenates, and subcellular fractions. Anal Biochem 157: 106-116, 1986.

18. Berger SP, Hunger M, Yard BA, Schnuelle P and Van Der Woude FJ: Dopamine induces the expression of heme oxygenase- 1 by human endothelial cells in vitro. Kidney Int 58: 2314-2319, 2000.

19. Allen DA, Harwood S, Varagunam M, Raftery MJ and Yaqoob MM: High glucose-induced oxidative stress causes apoptosis in proximal tubular epithelial cells and is mediated by multiple caspases. FASEB J 17: 908-910, 2003.

20. Hattori Y, Suzuki M, Hattori S and Kasai K: Vascular smooth muscle cell activation by glycated albumin (Amadori adducts). Hypertension 39: 22-28, 2002.

21. Ouedraogo R, Wu X, Xu SQ, et al: Adiponectin suppression of high-glucose-induced reactive oxygen species in vascular endothelial cells: evidence for involvement of a cAMP signaling pathway. Diabetes 55: 1840-1846, 2006.

22. Yokoi T, Fukuo K, Yasuda O, et al: Apoptosis signal-regulating kinase 1 mediates cellular senescence induced by high glucose in endothelial cells. Diabetes 55: 1660-1665, 2006.

23. Chen S, Cohen MP, Lautenslager GT, Shearman CW and Ziyadeh FN: Glycated albumin stimulates TGF-beta 1 production and protein kinase $\mathrm{C}$ activity in glomerular endothelial cells. Kidney Int 59: 673-681, 2001. 
24. Ayo SH, Radnik RA, Garoni JA, Glass WF II and Kreisberg JI: High glucose causes an increase in extracellular matrix proteins in cultured mesangial cells. Am J Pathol 136: 1339-1348, 1990.

25. Ziyadeh FN, Han DC, Cohen JA, Guo J and Cohen MP: Glycated albumin stimulates fibronectin gene expression in glomerular mesangial cells: involvement of the transforming growth factorbeta system. Kidney Int 53: 631-638, 1998.

26. Fukami K, Yamagishi S, Ueda S and Okuda S: Role of AGEs in diabetic nephropathy. Curr Pharm Des 14: 946-952, 2008.

27. Whiteside C, Wang H, Xia L, Munk S, Goldberg HJ and Fantus IG: Rosiglitazone prevents high glucose-induced vascular endothelial growth factor and collagen IV expression in cultured mesangial cells. Exp Diabetes Res 2009: 910783, 2009.

28. Lal MA, Brismar H, Eklof AC and Aperia A: Role of oxidative stress in advanced glycation end product-induced mesangial cell activation. Kidney Int 61: 2006-2014, 2002.

29. Yao D and Brownlee M: Hyperglycemia-induced reactive oxygen species increase expression of the receptor for advanced glycation end products (RAGE) and RAGE ligands. Diabetes 59: 249-255, 2010

30. Ziyadeh FN, Sharma K, Ericksen M and Wolf G: Stimulation of collagen gene expression and protein synthesis in murine mesangial cells by high glucose is mediated by autocrine activation of transforming growth factor-beta. J Clin Invest 93: 536-542, 1994.

31. Yang CW, Vlassara H, Peten EP, He CJ, Striker GE and Striker LJ: Advanced glycation end products up-regulate gene expression found in diabetic glomerular disease. Proc Natl Acad Sci USA 91: 9436-9440, 1994.

32. Gupta S, Clarkson MR, Duggan J and Brady HR: Connective tissue growth factor: potential role in glomerulosclerosis and tubulointerstitial fibrosis. Kidney Int 58: 1389-1399, 2000.

33. McLennan SV, Fisher E, Martell SY, et al: Effects of glucose on matrix metalloproteinase and plasmin activities in mesangial cells: possible role in diabetic nephropathy. Kidney Int Suppl 77: S81-S87, 2000.

34. Haneda M, Kikkawa R, Horide N, et al: Glucose enhances type IV collagen production in cultured rat glomerular mesangial cells. Diabetologia 34: 198-200, 1991.

35. Kolm-Litty V, Sauer U, Nerlich A, Lehmann R and Schleicher ED: High glucose-induced transforming growth factor betal production is mediated by the hexosamine pathway in porcine glomerular mesangial cells. J Clin Invest 101: 160-169, 1998.

36. Wolf G, Chen S and Ziyadeh FN: From the periphery of the glomerular capillary wall toward the center of disease: podocyte injury comes of age in diabetic nephropathy. Diabetes 54 : $1626-1634,2005$
37. Wendt TM, Tanji N, Guo J, et al: RAGE drives the development of glomerulosclerosis and implicates podocyte activation in the pathogenesis of diabetic nephropathy. Am J Pathol 162: 1123-1137, 2003

38. Shankland SJ: The podocyte's response to injury: role in proteinuria and glomerulosclerosis. Kidney Int 69: 2131-2147, 2006.

39. Stitt-Cavanagh E, MacLeod L and Kennedy C: The podocyte in diabetic kidney disease. Sci World J 9: 1127-1139, 2009.

40. Herbach N, Schairer I, Blutke A, et al: Diabetic kidney lesions of GIPRdn transgenic mice: podocyte hypertrophy and thickening of the GBM precede glomerular hypertrophy and glomerulosclerosis. Am J Physiol Renal Physiol 296: F819F829, 2009.

41. D'Agati V, Yan SF, Ramasamy R and Schmidt AM: RAGE, glomerulosclerosis and proteinuria: roles in podocytes and endothelial cells. Trends Endocrinol Metab 21: 50-56, 2010.

42. Lewko B and Stepinski J: Hyperglycemia and mechanical stress: targeting the renal podocyte. J Cell Physiol 221: 288-295, 2009.

43. Zhou LL, Hou FF, Wang GB, et al: Accumulation of advanced oxidation protein products induces podocyte apoptosis and deletion through NADPH-dependent mechanisms. Kidney Int 76: 1148-1160, 2009

44. Goligorsky MS, Chen J and Brodsky S: Workshop: endothelial cell dysfunction leading to diabetic nephropathy: focus on nitric oxide. Hypertension 37: 744-748, 2001.

45. Nakagawa T, Sato W, Glushakova O, et al: Diabetic endothelial nitric oxide synthase knockout mice develop advanced diabetic nephropathy. J Am Soc Nephrol 18: 539-550, 2007.

46. Isermann B, Vinnikov IA, Madhusudhan T, et al: Activated protein $\mathrm{C}$ protects against diabetic nephropathy by inhibiting endothelial and podocyte apoptosis. Nat Med 13: 1349-1358, 2007.

47. Satchell SC and Tooke JE: What is the mechanism of microalbuminuria in diabetes: a role for the glomerular endothelium? Diabetologia 51: 714-725, 2008.

48. Kelly DJ, Buck D, Cox AJ, Zhang Y and Gilbert RE: Effects on protein kinase C-beta inhibition on glomerular vascular endothelial growth factor expression and endothelial cells in advanced experimental diabetic nephropathy. Am J Physiol Renal Physiol 293: F565-F574, 2007. 